Research Paper

\title{
Comparison of Laparoscopic Versus Open Left Hemihepatectomy for Left-Sided Hepatolithiasis
}

\author{
Jung-Man Namgoong, Ki-Hun Kim ${ }^{\bowtie}$, Gil-Chun Park, Dong-Hwan Jung, Gi-Won Song, Tae-Yong Ha, \\ Duk-Bok Moon, Chul-Soo Ahn, Shin Hwang, Sung-Gyu Lee
}

Department of Surgery, University of Ulsan College of Medicine, Asan Medical Center, Seoul, Korea

$\square$ Corresponding author: Ki-Hun Kim, M.D., Ph.D., Department of Surgery, University of Ulsan College of Medicine, Asan Medical Center, 88, Olympic-ro 43-gil, Songpa-gu, Seoul 138-736, Korea. Tel: +82-10-4878-3495, +82-2-3010-3495; Fax: +82-2-3010-6701; E-mail: khkim620@amc.seoul.kr

( ) Ivyspring International Publisher. This is an open-access article distributed under the terms of the Creative Commons License (http://creativecommons.org/ licenses/by-nc-nd/3.0/). Reproduction is permitted for personal, noncommercial use, provided that the article is in whole, unmodified, and properly cited.

Received: 2013.08.28; Accepted: 2013.12.17; Published: 2014.0I.02

\begin{abstract}
PURPOSE: The purpose of this study was to evaluate and compare the perioperative and long-term outcomes of open versus laparoscopic left hemihepatectomy (OLH vs. LLH) for left-sided hepatolithiasis.

METHODS: Between October 2007 and June 2012, 149 patients with left-sided hepatolithiasis who underwent LLH $(n=37)$ or OLH $(n=112)$ were evaluated. The perioperative and long-term outcomes that were reviewed included the stone clearance rate, operative morbidity and mortality, and the stone recurrence rate.

RESULTS: The mean operative time of the LLH group was significantly longer than that of the OLH group $(257 \pm 50.4$ minutes vs. $237 \pm 75.5$ minutes, $p=0.022)$, but the mean hospital stay was significantly shorter $(8.8 \pm 4.10$ vs. $14.1 \pm 4.98$ days, $p<0.001)$. Postoperative complications were noted in four and twenty cases among LLH and OLH patients, respectively $(p=0.982)$. The initial clearance rate of intrahepatic duct (IHD) stones was $100 \%$ and $96.4 \%$ in the LLH and OLH groups, respectively, but all remnant stones ( $n=4$, OLH group) were resolved postoperatively. There were two cases of recurrence of IHD stones in OLH patients, but none in LLH patients $(p=0.28 \mathrm{I})$.

CONCLUSIONS: In left-sided hepatolithiasis, LLH was safe and effective: it resulted in low postoperative morbidity, no mortality and a high stone clearance rate, and there were no incidences of recurrence in our study. The potential benefits of LLH include a shorter hospital stay and a faster return to oral intake. If consideration is given to the appropriate indication criteria, including the extent of hepatectomy and the location and distribution of lesions, LLH may be an excellent choice for treatment of left-sided hepatolithiasis.
\end{abstract}

Key words: Laparoscopic left hemihepatectomy, intrahepatic duct stone, open left hemihepatectomy, left-sided hepatolithiasis, minimal invasive surgery

\section{Introduction}

Hepatolithiasis is defined as the presence of stones in the intrahepatic bile ducts [1,2]. It is classified as primary or secondary based on the causes of the disease. In the case of primary hepatolithiasis, stones are originally formed in the liver and accompany biliary strictures and local dilatation. They are typically generated in the gallbladder and the common bile duct (CBD), and then migrate to the liver to cause secondary hepatolithiasis. Primary hepatolithi- asis is very rare in Caucasians but common in East Asians [1]. Hepatolithiasis may also recur after removal of gallstones. To treat the disease effectively, intrahepatic duct (IHD) stones should be removed completely or as much as is possible, and causes of cholestasis such as biliary strictures, which could induce secondary hepatolithiasis, should also be eliminated [2]. Therefore, operative resection of hepatic parenchyma and bile ducts with inflammation and 
strictures is considered to be the best treatment option $[1,2]$.

Right or left hemihepatectomy and liver sectionectomy, as well as biliary drainage including lithotripsy after bile duct incision, are commonly employed to treat hepatolithiasis [2]. Although open hepatectomy is currently the standard approach to perform these procedures, laparoscopic hepatectomy is being increasingly performed for hepatolithiasis since the introduction of laparoscopic hepatectomy in 1992 by Gagner et al. [3].

Laparoscopic hepatectomy was first performed by the authors in June 2007, with hepatolithiasis included as an indication from October 2007. The objectives of this study were to evaluate and compare the safety and perioperative and long-term outcomes of laparoscopic left hemihepatectomy (LLH) versus open left hemihepatectomy (OLH) for left-sided hepatolithiasis.

\section{Materials and methods}

\section{Subjects}

Prior to this study, more than 400 cases of hepatectomy for hepatolithiasis had been performed by the authors, and the clinical indications have been previously reported [4]. The present study was based on a review of the perioperative and long-term outcomes from LLHs and OLHs that were performed to treat left-sided hepatolithiasis at Asan Medical Center, Seoul, between October 2007 and June 2012.

\section{Preoperative examination and classification of left-sided hepatolithiasis}

Each patient underwent one or more preoperative examinations including endoscopic retrograde cholangiopancreatography (ERCP), magnetic resonance cholangiography (MRC), or percutaneous transhepatic biliary drainage (PTBD), with the aim of characterizing the patient's biliary system anatomy and lesion pathology. In all cases, a liver dynamic computed tomography (LDCT), followed by the indocyanine green-15 minute retention rate (ICG-R15), was performed to confirm the presence of lesions and to determine the extent of hepatectomy.

The disease classification and operative strategy was based on the extent of atrophy of the left lobe and position of the left biliary strictures. The atrophic changes were classified as follows: unclear atrophy on $\mathrm{CT}$, mild atrophy with only one segment among segments II to IV or overall mild atrophy, moderate atrophy with more than $50 \%$ atrophy in the left lobe, and severe atrophy with almost no normal hepatic parenchyma. Left biliary strictures were classified into the following four types to provide a more accurate description (Fig. 1) [4]: type 1, strictures were located distally rather than in the bifurcation of $\mathrm{B} 4$ and $\mathrm{B} 2+3$ with noted dilatation of only $\mathrm{B} 2+3$ in most cases; type 2 , strictures were located in the bifurcation of $B 4$ and $\mathrm{B} 2+3$ or in the proximal bifurcation of $\mathrm{B} 4$ and $\mathrm{B} 2+3$ with dilatation of the entire left intrahepatic bile ducts (in these cases, severe atrophy of the left hepatic parenchyma and relative hypertrophy of the caudate lobe were commonly observed); type 3 , the presence of strictures or stones in the bile ducts of the caudate lobe; and type 4, the presence of strictures in both hepatic lobes.

\section{Patient selection}

LLH was performed for type 1,2, and 3 bile duct strictures, but was not considered for patients who had type 4 strictures, remnant bilateral stones, or remnant CBD stones even after ERCP or PTCS. To enable direct comparison, these inclusion and exclusion criteria were also applied to study participants in the OLH group. Bias was further reduced by excluding patients with extended left hemihepatectomy in the OLH group. Although middle hepatic vein (MHV) resection was not contraindicated for LLH, no LLH patient underwent MHV resection because a surgical goal of laparoscopic hepatectomy was preservation of the MHV. Patients with a pathologically confirmed benign result who were preoperatively diagnosed with cholangiocarcinoma were also excluded, as were patients who received concomitant procedures with left hemihepatectomy.

\section{Operative techniques}

\section{I) Open left hemihepatectomy (OLH)}

OLH was performed under general anesthesia with the patient in the supine position. Routinely, a reversed L-shaped incision was performed, although a midline incision was also performed depending on previous operation history. The left hepatic artery and left portal vein were individually dissected, ligated, and divided. Then, the left bile duct and left hepatic vein were ligated, divided, and closed after hepatic parenchymal resection.

Exploration of the CBD was performed when massive stones required removal. If access to the right IHD was required because of encompassed strictures or remnant stones, intraoperative cholangioscopy was used to due to its challenging surgical proximity. A Cavitron Ultrasonic Surgical Aspirator (CUSA EXcel $^{\mathrm{TM}}$; Valleylab, Boulder, Colorado, USA) was used in hepatic parenchymal resection. Pringle's maneuver was employed in 96 of 112 cases of OLH. Intra-abdominal drainage with a Jackson-Pratt (JP) drain was performed in all cases of OLH. 


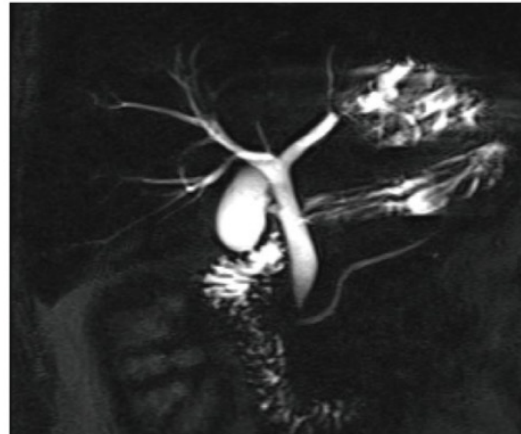

A Type 1

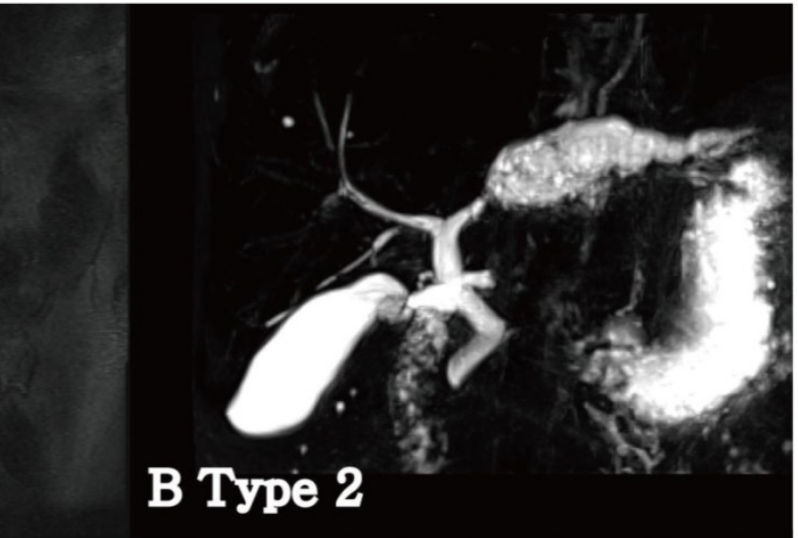

\section{Type 3}

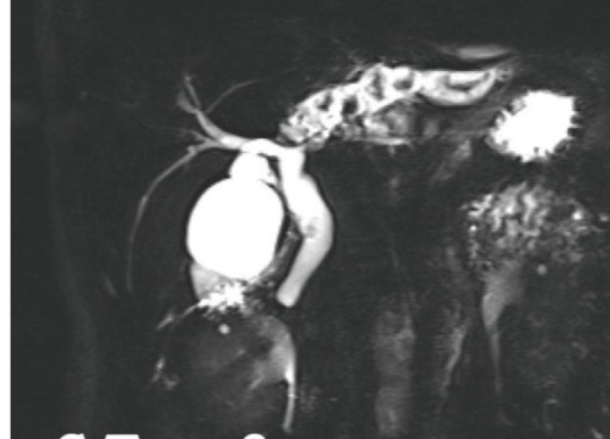

(B)

Figure I. Classification of the left hepatic strictures in patients with left-sided hepatolithiasis. (A) Type I: Stricture was confined to one segment. B2+3 was usually involved. (B) Type 2: Stricture was located near the confluence of B4. B4 and B2+3 were concurrently dilated. (C) Type 3: Stricture was extended to the caudate duct portion. Concomitant resection of the caudate lobe was usually performed in the biliary stricture of this type. (D) Type 4: Multiple stones and strictures existed in the right and left lobes.

\section{2) Laparoscopic left hemihepatectomy (LLH)}

LLH was performed under general anesthesia with the patient positioned supine with the two legs apart. First, a pneumoperitoneum at $12 \mathrm{mmHg}$ by $\mathrm{CO}_{2}$ gas was established in the umbilical region with a Veress needle, and a $10 \mathrm{~mm}$ trocar was placed in the upper umbilical region. After confirming the integrity of the intraperitoneal cavity by $30^{\circ}$ laparoscopy, the main working trocar was inserted in the right side of the patient, $5 \mathrm{~cm}$ lateral to the epigastric midline. A 10 $\mathrm{mm}$ trocar for minor working and operator traction was inserted in the right flank of the patient, and another $5 \mathrm{~mm}$ trocar for the first assistant was inserted in the left flank. For suction and traction, a $10 \mathrm{~mm}$ trocar was placed 3 to $5 \mathrm{~cm}$ away from the bottom of the xiphisternum (Fig. 2) [5-7].

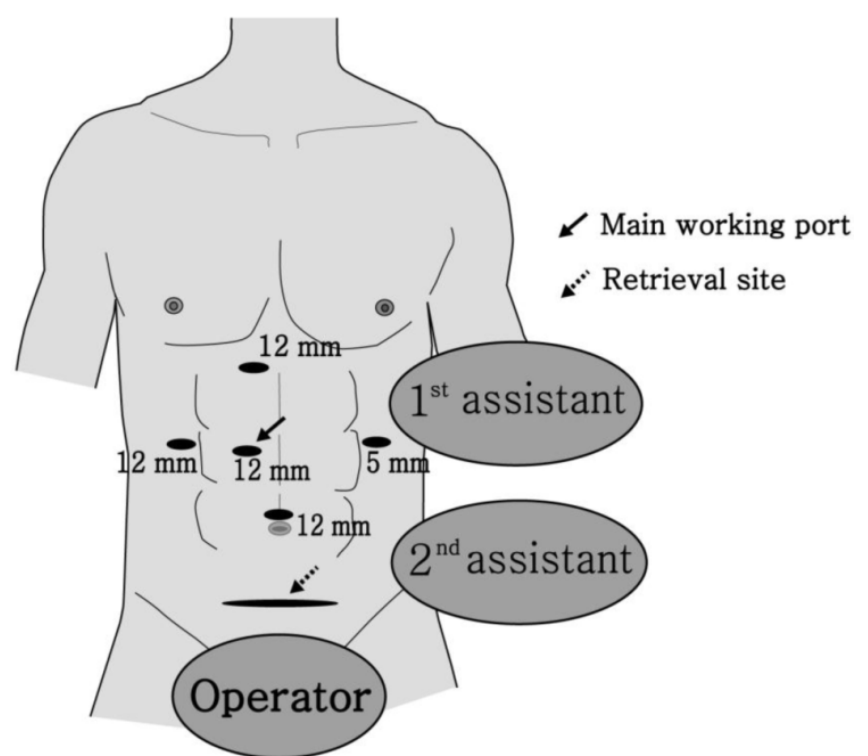

Figure 2. The trocar locations of left-sided laparoscopic liver resection 
The operator used two trocars on the right side of the patient and the assistant performed traction of the liver and suction via the two trocars on the midline and left side of the patient. The falciform and coronary ligaments were dissected using ultrasonic shears (Harmonic scalpel ${ }^{\mathrm{TM}}$; Ethicon Endosurgery, Cincinnati, USA), and then the round ligament was ligated and divided utilizing a Hem-o-lok ${ }^{\circledR}$ clip (Weck Closure System, Research Triangle Park, North Carolina, USA). Next, the left hepatic artery and left portal veins were ligated and divided via individual dissection, and the range of hepatic parenchymal resection was determined by assessing ischemic penumbral changes of the left hepatic parenchyma. The location of the MHV was confirmed via laparoscopic ultrasonography. Hepatic parenchymal dissection was performed using the Harmonic scalpel ${ }^{\mathrm{TM}}$, LigaSure ${ }^{\mathrm{TM}}$ (Valleylab, Boulder, Colorado, USA), and CUSA EXcel $^{\mathrm{TM}}$. After parenchymal resection, Endo-GIA (Echelon Flex ${ }^{\mathrm{TM}}$; Ethicon Endosurgery, Cincinnati, USA) was used to ligate the left hepatic veins and bile ducts. A panel incision of approximately $7 \mathrm{~cm}$ length was created at the suprapubic area and then the specimen was removed.

\section{Follow-up examination}

In all patients, LDCT scans and liver function tests were performed at postoperation 1 week, 1 month, 6 months, and 1 or 2 years at the outpatient clinic. In cases of postoperative remnant stone or recurrence, the stones were removed via ERCP or PTCS after a PTBD insertion.

\section{Results}

A total of 229 patients underwent left hemihepatectomy for left-sided hepatolithiasis during the study period. Of these patients, 37 patients underwent LLH for type 1, type 2, and type 3 bile duct strictures. The distributions of patients by year and procedure type are shown in Figure 3. Among 192 OLH patients, 112 were included in the study, and 80 were excluded (25 patients had type 4 biliary strictures or bilateral stones; 19 patients had CBD strictures or stones after preoperative ERCP or PTCS; nine patients had been preoperatively diagnosed with cholangiocarcinoma; 14 patients had had one or more concomitant procedures with OLH; and 13 patients had undergone MHV resection). Among the 149 study patients, 49 were male and 100 female (male:female $=1: 2$ ), with a mean age of 56.0 years (range, 28 to 80 years). Four LLH and twelve OLH patients had a previous operation history (Table 1). There were no intergroup differences in preoperative ICG-R15 and blood-test markers including hemoglobin, platelet counts, total bilirubin, and AST/ALT (Table 2).

The mean duration of operation for the OLH group, the duration from skin incision to skin closure, was significantly shorter than that for the LLH group (Table 3). Additionally, the LLH group showed less bleeding and a lower rate of transfusion. An additional caudate lobectomy was performed in one LLH patient (out of three) and 15 OLH patients for type 3 stricture $(p=0.121)$. The mean postoperative time to oral intake was shorter in the LLH group than in the OLH group (2.2 \pm 0.48 days vs. $2.8 \pm 0.46$ days, $p<$ $0.001)$. The LLH group showed a significantly shorter mean postoperative hospital stay than the OLH group (8.8 \pm 4.10 days vs. $14.1 \pm 4.98$ days, $p<0.001)$. Four LLH and twenty OLH patients exhibited postoperative complications, but there was no difference in the rate of complications (Table 3).

LLH (total number=37)

- left hemihepatectomy (total number=229)

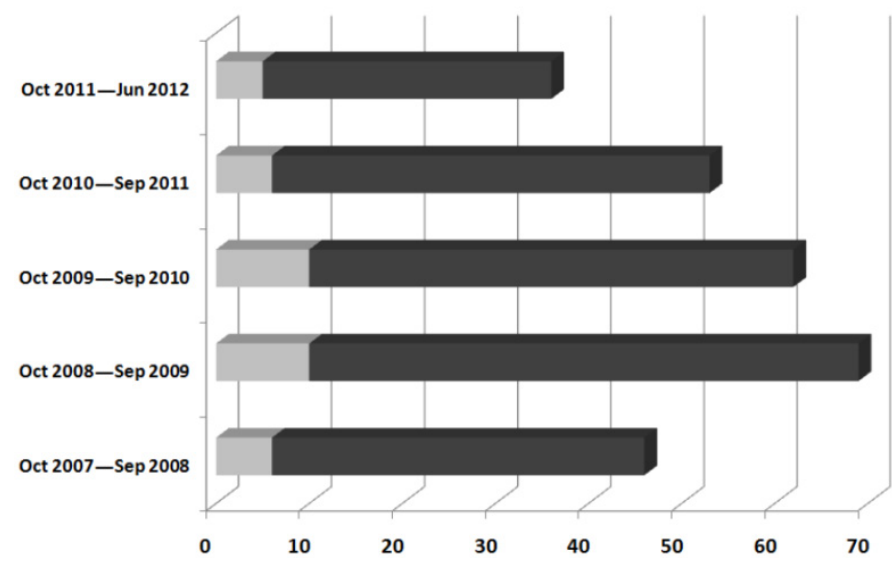

Number

Figure 3. The distribution of patients by year and procedure type. 
Table I. Clinical and demographic features of patients

\begin{tabular}{|c|c|c|c|}
\hline Variable & LLH $(n=37)$ & $\begin{array}{l}\text { OLH } \\
(n=112)\end{array}$ & p-value \\
\hline Age (yr), mean \pm SD & $53.0 \pm 10.89$ & $59.1 \pm 8.40$ & 0.003 \\
\hline Gender (male:female) & $9: 28$ & $40: 72$ & 0.311 \\
\hline Liver disease & $0(0)$ & $4(3.6)$ & 0.572 \\
\hline HBV & $0(0)$ & $4(3.6)$ & 0.572 \\
\hline $\mathrm{HCV}$ & $0(0)$ & $0(0)$ & - \\
\hline $\begin{array}{l}\text { Past history of abdominal } \\
\text { surgery, number (n) }\end{array}$ & $4(10.8)$ & $10(8.9)$ & 1.000 \\
\hline Cholecystectomy & $0(0)$ & $4(3.6)$ & 0.572 \\
\hline Appendectomy & $2(5.4)$ & $3(2.7)$ & 0.598 \\
\hline Cesarean section & $2(5.4)$ & $3(2.7)$ & 0.598 \\
\hline Gastrectomy & $0(0)$ & $0(0)$ & \\
\hline Colon resection & $0(0)$ & $2(1.8)$ & 0.413 \\
\hline \multicolumn{4}{|l|}{ Preoperative examinations } \\
\hline MRCP & $33(89.2)$ & $73(65.2)$ & 0.001 \\
\hline ERCP & $15(40.5)$ & $41(36.6)$ & 0.473 \\
\hline PTCS & $3(3.1)$ & $17(15.2)$ & 0.401 \\
\hline \multicolumn{4}{|l|}{$\begin{array}{l}\text { Types of left-sided hepato- } \\
\text { lithiasis }\end{array}$} \\
\hline Type 1 & $20(54.1)$ & $50(44.6)$ & 0.320 \\
\hline Type 2 & $14(37.3)$ & $39(34.8)$ & 0.816 \\
\hline Type 3 & $3(8.1)$ & $23(20.5)$ & 0.084 \\
\hline Parenchymal atrophy & $19(51.4)$ & $73(65.2)$ & 0.137 \\
\hline mild ( $5<$ atrophy $\leq 20)$ & $11(29.7)$ & $19(17.0)$ & 0.077 \\
\hline moderate $(20<$ atrophy $\leq 50)$ & $7(18.9)$ & $46(41.1)$ & 0.011 \\
\hline severe (50<atrophy) & $1(2.7)$ & $8(7.1)$ & 0.326 \\
\hline \multicolumn{4}{|c|}{$\begin{array}{l}\text { Values are presented as mean } \pm \text { SD or number }(\%) \text {. } \\
\mathrm{MRCP}=\text { magnetic resonance cholangiopancreatography; } \mathrm{ERCP}=\text { endoscopic } \\
\text { retrograde cholangiopancreatography; PTCS = percutaneous transhepatic cholan- } \\
\text { gioscopy. }\end{array}$} \\
\hline \multicolumn{4}{|c|}{ Table 2. Preoperative laborative findings } \\
\hline Variable & LLH $(n=37)$ & OLH $(n=112)$ & $\mathrm{p}$-value \\
\hline Hemoglobin $(\mathrm{g} / \mathrm{dl})$ & $13.0 \pm 1.28$ & $12.9 \pm 1.43$ & 0.874 \\
\hline Creatinine $(\mathrm{mg} / \mathrm{dL})$ & $0.7 \pm 0.14$ & $0.7 \pm 0.14$ & 0.694 \\
\hline INR & $1.0 \pm 0.07$ & $1.0 \pm 0.09$ & 0.397 \\
\hline Total bilirubin (mg/dL) & $0.85 \pm 0.27$ & $0.84 \pm 0.29$ & 0.794 \\
\hline AST (IU/L) & $26.7 \pm 17.45$ & $24.4 \pm 10.31$ & 0.457 \\
\hline ALT (IU/L) & $32.4 \pm 41.54$ & $23.8 \pm 16.25$ & 0.071 \\
\hline $\operatorname{Albumin}(\mathrm{g} / \mathrm{dL})$ & $3.9 \pm 0.39$ & $3.8 \pm 0.40$ & 0.526 \\
\hline ICG-R15 (\%) & $10.5 \pm 5.53$ & $11.5 \pm 9.26$ & 0.472 \\
\hline
\end{tabular}

Values are presented as mean $\pm \mathrm{SD}$.

Remnant stones were not found in any LLH patient but occurred in four OLH patients. In the latter case, remnant stones were removed postoperatively by PTCS. There were two cases of stone recurrence in the OLH group, whereas there were none in the LLH group $(p=0.281)$. The recurred stones in the two OLH patients were found in the fifth and eighth segment of the right liver, respectively. There was no significant intergroup difference in either the incidence of remnant stones or the recurrence rate (Table 4). There was no incidence of perioperative or long-term mortality in either group.
Table 3. Perioperative outcomes

\begin{tabular}{|c|c|c|c|}
\hline Variable & LLH $(n=37)$ & $\begin{array}{l}\text { OLH } \\
(\mathrm{n}=112)\end{array}$ & $\mathrm{p}$-value \\
\hline Duration of operation (min) & $257 \pm 50.4$ & $237 \pm 75.5$ & 0.022 \\
\hline $\begin{array}{l}\text { Intraoperative transfusion } \\
\text { (patient number) }\end{array}$ & $0(0)$ & $10(9)$ & 0.048 \\
\hline Intraoperative bleeding $(\mathrm{mL})$ & $280 \pm 96.9$ & $347 \pm 285.5$ & 0.035 \\
\hline Resection of Caudate lobe & $1(2.7)$ & 15 (13.4) & 0.121 \\
\hline T-tube insertion & $0(0)$ & $5(4.5)$ & 0.333 \\
\hline Time to oral intake (day) & $2.2 \pm 0.48$ & $2.8 \pm 0.46$ & $<0.001$ \\
\hline $\begin{array}{l}\text { Postoperative hospital stay } \\
\text { (day) }\end{array}$ & $8.8 \pm 4.10$ & $14.1 \pm 4.98$ & $<0.001$ \\
\hline Postoperative complication & $4(10.8)$ & $20(17.8)$ & 0.982 \\
\hline Liver-related complications & $2(5.4)$ & $3(2.7)$ & 0.598 \\
\hline Bile leakage & $0(0)$ & $1(0.8)$ & 0.564 \\
\hline $\begin{array}{l}\text { Intra-abdominal fluid col- } \\
\text { lection }\end{array}$ & $2(5.4)$ & $2(1.7)$ & 0.257 \\
\hline Infectious complications & $2(5.4)$ & $17(15.2)$ & 0.160 \\
\hline Intra-abdominal abscess & $0(0)$ & $4(3.6)$ & 0.151 \\
\hline Wound abscess & $2(5.4)$ & $12(10.7)$ & 0.337 \\
\hline Pneumonia & $0(0)$ & $1(0.8)$ & 0.564 \\
\hline \multicolumn{4}{|l|}{ Dindo-Clavien classification } \\
\hline Grade I & $2(5.4)$ & $7(6.3)$ & 0.852 \\
\hline Grade II & $2(5.4)$ & $11(9.8)$ & 0.409 \\
\hline Grade IIIa/IIIb & $0(0) / 0(0)$ & $\begin{array}{l}2(1.7) / 0 \\
(0)\end{array}$ & 0.413 \\
\hline Grade IV & $0(0)$ & $0(0)$ & - \\
\hline Postoperative mortality & $0(0)$ & $0(0)$ & - \\
\hline
\end{tabular}

Values are presented as mean \pm SD or number $(\%)$.

Table 4. The stone clearance and recurrence rate

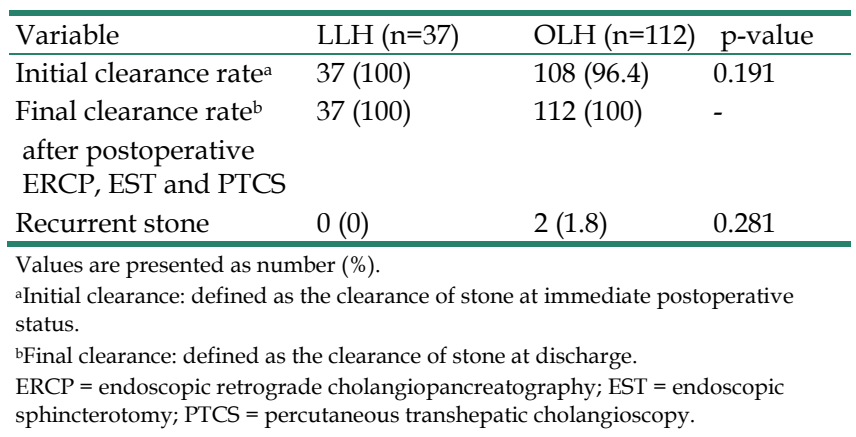

\section{Discussion}

Hepatolithiasis has a high recurrence rate and its symptoms are commonly observed in individuals in their fifth or sixth decade of life. In general, patients who have hepatolithiasis without extrahepatic stones are in their forties or fifties, while those who have hepatolithiasis with extrahepatic stones are in their sixties or seventies. It is also known that women are more susceptible to the disease than men (women:men, 1.2:1) [8]. Hepatolithiasis tends to be intractable when it is accompanied by repetitive cholangitis, hepatic parenchymal atrophy, and/or cholangiocarcinoma, requiring active treatment after diagnosis. Lesions of the bile duct such as IHD stricture and di- 
latation should be considered in the treatment plan, and hepatic parenchyma resection is regarded as the best treatment option $[1,2,4,9]$. Hepatectomy is advantageous for simultaneous elimination of stones and bile duct strictures, resection of hepatic parenchyma with irreversible changes, and removal of potential intrahepatic bile duct cancer. In a previous study, 427 patients who received treatment for hepatolithiasis were divided into three groups: a hepatectomy group, a group in which patients underwent surgery other than hepatectomy, and a non-surgical group; the hepatectomy group showed the lowest recurrence rate $(9.5 \%)$, mortality $(2.5 \%)$, and secondary biliary cirrhosis (2.1\%) [10].

In general, the left lobe of the liver is prone to hepatolithiasis. In cases where hepatolithiasis is limited to the left lobe only, left hemihepatectomy is an appropriate treatment option: it has a low risk of severe operative complications and allows removal of the causes of left-sided hepatolithiasis, including strictures $[4,11]$. By contrast, right-sided hepatolithiasis has a low incidence and commonly accompanies bile duct strictures around the hilar area. It also has a higher frequency of bilateral stones, thereby lessening the appropriateness of hepatectomy as a treatment option [12].

Although the indications of laparoscopic hepatectomy are yet to be clearly established, resectable benign diseases, benign tumors, localized hepatocellular carcinoma, metastatic liver cancer, and restricted small IHD malignancy can generally be considered as indications [13]. Based on the location of the lesions, most laparoscopic hepatectomies have been restricted to cases where there were only one or two segments in the lateral area (Couinaud second to sixth segment). In addition, major laparoscopic liver resection including right hemihepatectomy is performed by only a limited number of experts, with equivalent safety and efficacy to open surgery having been shown only in a few highly specialized centers. However, laparoscopic left lateral liver sectionectomy is recommended as a gold standard for resection of lesions located in segments II and III [14]. Moreover, Belli et al. [15] reported that LLH could evolve as a new standard for care.

Recently many studies have reported the advantages of laparoscopic liver resection over an open technique, including less blood loss and complications, despite its comparatively longer operation time [16-18]. In one study [18], patients who received laparoscopic hepatectomy (of less than two segments) did not show differences to an open procedure in intraoperative blood loss and parenchymal hepatic resection rate, but showed reduced postoperative analgesic dose, reduced time to oral intake, and a reduced duration of postoperative hospital stay. We found that there was an increase in operative time of just 20 minutes with LLH. Moreover, the mean duration of operation in the last ten cases of LLH was $240 \pm 25.2$ minutes, which was not significantly longer than the mean duration of OLH cases ( $p=0.874)$.

Massive bleeding is the major concern in laparoscopic hepatectomy and is the main cause of conversion to an open operation $[3,19]$. CUSA EXcel ${ }^{\mathrm{TM}}$, LigaSure $^{\mathrm{TM}}$ and ultrasonic shears are now commonly used for hepatic parenchyma resection to reduce bleeding. We also utilized these methods whilst performing hepatectomy. For division of hepatic veins and Glisson's sheath, an endo-clip (Ligaclip ${ }^{\circledR}$; Ethicon Endosurgery, Cincinnati, USA) and Hem-o-lok ${ }^{\circledR}$ clip can be employed when the structures are small in size, and a knot-pusher ${ }^{\mathrm{TM}}$ (Edwards, Utah, USA) or Endo-GIA can be used when large. The use of these devices can be credited to minimizing blood loss. It has also been reported that Pringle's maneuver can be utilized to reduce bleeding [20]; we also utilized this technique if required to reduce intraoperative bleeding.

There have been only a limited number of studies on laparoscopic hepatectomy for hepatolithiasis and, in particular, the use of LLH as a routine approach for left-sided hepatolithiasis. When lesions are located at the bile duct bifurcation, the presence of strictures in each bile duct should be confirmed. Since bile duct cancer can exist in strictures, examination should be carefully performed and be followed by pathologic confirmation. Moreover, hepatolithiasis may be accompanied by adhesions to the surrounding tissues. In most cases of hepatolithiasis, atrophy and/or anatomical changes existed in the hepatic parenchyma, and intraoperative bleeding was increased when the lesions with hepatic atrophy were resected [19]. In this study, left lobe atrophy was observed in 92 patients $(61.9 \%)$, and, interestingly, more intraoperative bleeding was observed in OLH patients (Table 1). Because $55.4 \%$ (62 cases) of OLH and $45.9 \%$ (17 cases) of LLH patients had lesions in B4 (type 2 and 3), whereas $41 \%$ (46 cases) of OLH and 19\% (7 cases) of LLH patients had moderate atrophy, the increased intraoperative bleeding seen in the OLH group ( $p=0.033)$ may have been due to the increased incidence of atrophy. Further assessment of multiple factors related to safety and efficacy is required to determine the suitability of laparoscopic hepatectomy in hepatolithiasis.

A number of postoperative complications are associated with hepatolithiasis. IHD stones are commonly infected so that intra-abdominal contamination as well as infectious complications such as intra-abdominal abscesses and wound abscessed are 
likely to occur [21]. We noted four (10.8\%) and twenty $(17.8 \%)$ cases of complications in LLH and OLH patients, respectively. Wound abscesses were noted in two $(5 \%)$ and twelve $(10.7 \%)$ of LLH and OLH patients, respectively $(p=0.337)$. Although the difference was not significant, the rate of wound abscess after OLH was in agreement with that found in other studies. The two cases of wound abscess in the LLH patients did not influence the length of their hospital stay.

Laparoscopic hepatectomy is becoming increasingly popular, and hepatolithiasis is now being included as an indication for its use. We found that LLH could be safely and effectively performed for left-sided hepatolithiasis, and resulted in postoperative morbidity rates similar to those of an open procedure, with no mortality, a high stone clearance, and low recurrence rates in unilateral left hepatolithiasis. The potential benefits of LLH include a shorter hospital stay and a faster return to oral intake. If consideration is given to the appropriate indication criteria, including the extent of hepatectomy and the location and distribution of lesions, LLH may be an excellent choice for the treatment of left-sided hepatolithiasis.

\section{Competing Interests}

The authors have declared that no competing interest exists.

\section{References}

1. Yang T, Lau WY, Lai EC, et al. Hepatectomy for bilateral primary hepatolithiasis: a cohort study. Ann Surg. 2010; 251(1): 84-90.

2. Li SQ, Liang LJ, Peng BG, et al. Outcomes of liver resection for intrahepatic stones: a comparative study of unilateral versus bilateral disease. Ann Surg. 2012; 255(5): 946-953.

3. Gagner M, Rogula T, Selzer D. Laparoscopic liver resection: benefits and controversies. Surg Clin North Am. 2004; 84(2): 451-462.

4. Cheong O, Hwang S, Song GW, et al. Analysis on the Clinical Significance of Biliary Exploration through the Left Hepatic Duct Opening during Left Hepatectomy for the Patients with Hepatolithiasis. Korean J Hepatobiliary Pancreat Surg. 2005; 9(4): 203-209.

5. Kim KH, Jung DH, Park KM, et al. Comparison of open and laparoscopic live donor left lateral sectionectomy. Br J Surg. 2011; 98(9): 1302-1308.

6. Yu YD, Kim KH, Jung DH, et al. Laparoscopic Live Donor Left Lateral Sectionectomy is Safe and Feasible for Pediatric Living Donor Liver Transplantation. Hepato-Gastroenterol. 2012; 59(120): 2445-2449.

7. Choi NK, Kim $\mathrm{KH}$, Jung $\mathrm{DH}$, et al. Laparoscopic liver resection for hepatocellular carcinoma: a three-year study of 57 Patients. Hepatogastroenterology. 2013; 60(121): 144-148.

8. Mori T, Sugiyama M, Atomi Y. Gallstone disease: Management of intrahepatic stones. Best Pract Res Clin Gastroenterol. 2006; 20(6): 1117-1137.

9. Han HS, Yi NJ. Laparoscopic treatment of intrahepatic duct stone. Surg Laparosc Endosc Percutan Tech. 2004; 14(3): 157-162.

10. Jan YY, Chen MF, Wang CS, et al. Surgical treatment of hepatolithiasis: long-term results. Surgery. 1996; 120(3): 509-514.

11. Hwang JH, Yoon YB, Kim YT, et al. Risk factors for recurrent cholangitis after initial hepatolithiasis treatment. J Clin Gastroenterol. 2004; 38(4): 364-367.

12. Ha TK, Choi CS, Choi YK, et al. Hepatic resection for right sided intrahepatic stones. Korean J HBP Surg 2005; 9(1): 31-35.

13. Hwang DW, Han HS, Yoon YS, et al. Totally anatomic laparoscopic right anterior sectionectomy. J Laparoendosc Adv Surg Tech A. 2012; 22(9): 913-916.

14. Dokmak S, Raut V, Aussilhou B, et al. Laparoscopic left lateral resection is the gold standard for benign liver lesions: a case-control study. HPB (Oxford). 2013.

15. Belli G, Gayet B, Han HS, et al. Laparoscopic left hemihepatectomy a consideration for acceptance as standard of care. Surg Endosc. 2013; 27(8): 2721-2726.
16. Laurent A, Cherqui D, Lesurtel $\mathrm{M}$, et al. Laparoscopic liver resection for subcapsular hepatocellular carcinoma complicating chronic liver disease. Arch Surg. 2003; 138(7): 763-769; discussion 769.

17. Lesurtel M, Cherqui D, Laurent A, et al. Laparoscopic versus open left lateral hepatic lobectomy: a case-control study. J Am Coll Surg. 2003; 196(2): 236-242.

18. Rau HG, Buttler E, Meyer G, et al. Laparoscopic liver resection compared with conventional partial hepatectomy--a prospective analysis. Hepatogastroenterology. 1998; 45(24): 2333-2338.

19. Yoon YS, Han HS, Shin SH, et al. Laparoscopic treatment for intrahepatic duct stones in the era of laparoscopy: laparoscopic intrahepatic duct exploration and laparoscopic hepatectomy. Ann Surg. 2009; 249(2): 286-291.

20. Dulucq JL, Wintringer $P$, Stabilini $C$, et al. Laparoscopic liver resections: a single center experience. Surg Endosc. 2005; 19(7): 886-891.

21. Liu CL, Fan ST, Wong J. Primary biliary stones: Diagnosis and management. World J Surg. 1998; 22(11): 1162-1166. 